УДК 550.46

\title{
РЕГИОНАЛЬНЫЕ ОСОБЕННОСТИ ЭКОЛОГО-ГЕОХИМИЧЕСКОГО СОСТОЯНИЯ ПОВЕРХНОСТНЫХ ВОДНЫХ ОБЪЕКТОВ В ТАЕЖНОЙ ЗОНЕ ЗАПАДНОЙ СИБИРИ
}

\author{
Марков Михаил Леонидович1, \\ 2019mml@mail.com

\section{Потапова Татьяна Михайловна²,} \\ ptm2000@mail.ru \\ Задонская Ольга Викторовна1, \\ ov-zadon@yandex.ru \\ 1 Государственный гидрологический институт, \\ Россия, 199053, г. Санкт-Петербург, Васильевский остров, 2-я линия, 23. \\ 2 Санкт-Петербургский государственный университет, \\ Россия, 199034, г. Санкт-Петербург, Университетская набережная, 7/9.
}

\begin{abstract}
Актуальность. Количественная оценка эколого-геохимического состояния поверхностных вод и фракторов их формирования является одним из важнейших этапов управления водными ресурсами, определяющим эффрективность мероприятий по комплексному использованию и охране вод.

Цель: количественная оценка региональных особенностей современного эколого-геохимического состояния поверхностных водных объектов в таежной зоне Западной Сибири.

Методы: методы определения химического состава вод: титриметрический, турбидиметрический, фотометрический, ионная хроматография, инверсионно-вольт-амперометрический, атомно-абсорбционный, масс-спектрометрический с индуктивно-связанной плазмой; статистические методы.

Результаты и выводы. По результатам анализа материалов многолетних гидрохимических наблюдений Росгидромета и ряда других организаций рассмотрены региональные особенности эколого-геохимического состояния поверхностных водных объектов в таежной зоне Западной Сибири. Показано, что химический состав поверхностных вод в регионе в значительной степени определяется природными процессами заболачивания, вследствие чего наблюдается нарушение рыбохозяйственных и хозяйственно-питьевых нормативов качества по величине $\mathrm{pH}$, содержанию $\mathrm{NH}_{4}^{+}, \mathrm{Fe}, \mathrm{Al}, \mathrm{Mn}$, фенолов, веществ, идентифицируемых как «нефтепродукты», а также рыбохозяйственных нормативов - по содержанию $\mathrm{NO}_{2}^{-}$, фоосфратов, Cu, $\mathrm{Zn}$ и хозяйственно-питьевых - по величине бихроматной и перманганатной окисляемости. Установлено, что антропогенное влияние достаточно надежно выявляется по повышению содержаний хлорид-иона (в пределах предельно допустимых кониентраций, но в 2-3 раза выше фоновых значений). Разработаны рекомендации по организации процесса оценки гидрохимического фона. На основе региональных фоновых концентраций загрязняющих веществ и расходов воды на режимных створах сибирских рек могут быть определены степени разбавления сточных вод, сбрасываемых в реки, с сильно заболоченными водосборами. Эти расчеты должны быть положены в основу утвержденных нормативов допустимых воздействий на речную сеть таежной зоны Западной Сибири.
\end{abstract}

\section{Ключевые слова:}

Воды речные, озерные воды, болотные воды, химический состав, таежная зона, Западная Сибирь.

\section{Введение}

Таежная зона Западно-Сибирской равнины занимает площадь около 1,2 млн км², примерно 90 \% которой приходится на бассейн р. Обь. Ключевой особенностью этой территории являются интенсивная нефтегазодобыча, в процессе которой ежедневно сжигается 6-7 млрд м ${ }^{3}$ попутного газа, размещается огромное количество отходов бурения и происходит не менее одной аварии с потерей в среднем 2 т нефти, причем общие потери углеводородов достигают 7-20\% от суммарной добычи [1-3]. Другая важная особенность - исключительно высокая заболоченность водосборов с продолжающимся приростом торфяной залежи со скоростью примерно 1 мм/год $[4,5]$. Все вместе это определяет современное экологогеохимическое состояние поверхностных водных объектов в таежной зоне Западной Сибири, характеризующееся распространением пресных вод с преобладанием в ионном составе, как правило, $\mathrm{HCO}_{3}{ }^{-}$и $\mathrm{Ca}^{2+}$, высоким содержанием органических веществ и продуктов их трансформации, в том числе в концентрациях, существенно превышающих установленные предельно допустимые значения для водных объектов хозяйственно-питьевого и рыбохозяйственного назначения [6-8]. На основе региональных фоновых концентраций загрязняющих веществ и расходов воды на режимных створах сибирских рек могут быть определены степени разбавления сточных вод, сбрасываемых в реки с сильно заболоченными водосборами. Эти расчеты должны быть положены в основу утвержденных нормативов допустимых воздействий на речную сеть таежной зоны Западной Сибири.

С учетом указанных особенностей и в целях повышения эффективности экологического мониторинга и планируемых на его результатах природоохранных мероприятий требуется количественная оценка факторов формирования эколого-геохимического состояния поверхностных вод региона и допустимых антропо- 
генных воздействий на водные объекты. Первым этапом решения подобной задачи является комплексная оценка современного эколого-геохимического состояния водных объектов, что и определило содержание рассматриваемой работы. Основное внимание было уделено изучению водных объектов в бассейне р. Оби на территории Томской области и Ханты-Мансийского автономного округа.

\section{Исходная информация и методика исследования}

В качестве исходной информации использованы опубликованные данные многолетних наблюдений Росгидромета на реках, материалы экспедиционных исследований рек, озер, болот, подземных вод Государственного гидрологического института (ГГИ), Томского политехнического университета (ТПУ), ОАО «Томскгеомониторинг», Томского филиала Института геологии и геофизики Сибирского отделения Российской Академии наук (ТФ ИГНГ СО РАН), полученные при непосредственном участии и/или под руководством авторов совместно с С.М. Новиковым и О.Г. Савичевым [6-9], а также сведения других организаций и авторов [10-17].

Основное условие обобщения информации из разных источников - отбор проб согласно требованиям [18] и определение гидрохимических показателей в аккредитованных лабораториях (в основном в подразделениях Росгидромета, в Санкт-Петербургском государственном университете (СПбГУ), ТПУ, АО «Томскгеомониторинг») по аттестованным и сопоставимым между собой методикам. Для получения общей характеристики химического состава вод использовались данные о $\mathrm{pH}$, сумме $\Sigma$ и собственно содержаниях главных ионов $\left(\mathrm{Ca}^{2+}, \mathrm{Mg}^{2+}, \mathrm{Na}^{+}, \mathrm{K}^{+}, \mathrm{HCO}_{3}^{-}\right.$, $\mathrm{SO}_{4}{ }^{2-}, \mathrm{Cl}^{-}$), для оценки содержания органических веществ - концентрации веществ, идентифицируемых как «нефтепродукты», и косвенные показатели - перманганатная (PO - permanganate oxidation) и бихроматная (BO - bichromate oxidation) окисляемости, для оценки специфических условий - концентрации биогенных веществ $\left(\mathrm{Si}, \mathrm{NO}_{3}^{-}, \mathrm{NO}_{2}^{-}, \mathrm{NH}_{4}^{+}\right.$, фосфаты) и ряда металлов ( $\mathrm{Fe}, \mathrm{Cu}, \mathrm{Zn}, \mathrm{Pb}, \mathrm{Cd}, \mathrm{Hg})$. Используемые методы анализа преимущественно: $\mathrm{pH}$ - потенциометрический; концентрации $\mathrm{Ca}^{2+}, \mathrm{Mg}^{2+}, \mathrm{HCO}_{3}{ }^{-}, \mathrm{CO}_{3}{ }^{2-}$, $\mathrm{Cl}^{-}, \mathrm{CO}_{2}, \mathrm{PO}$ и ВО - титриметрический; $\mathrm{SO}_{4}{ }^{2-}$ - турбидиметрический; $\mathrm{Si}, \mathrm{NH}_{4}^{+}, \mathrm{NO}_{2}^{-}, \mathrm{NO}_{3}^{-}$, фосфаты, $\mathrm{Fe}$ - фотометрический, масс-спектрометрический с индуктивно-связанной плазмой с использованием массспектрометра NexION 300D; $\mathrm{Na}^{+}, \mathrm{K}^{+}$- ионная хроматография; $\mathrm{Zn}, \mathrm{Cu}, \mathrm{Al}$ - инверсионно-вольтамперометрический, атомно-абсорбционный, массспектрометрический с индуктивно-связанной плазмой.

Последующая обработка заключалась в поиске и исключении экстремальных значений согласно [19], расчете средних арифметических значений $A$ и погрешностей их определения по формуле $\delta_{A}$ :

$$
\delta_{A} \approx \frac{\sigma}{\sqrt{N}}
$$

где $\sigma$ - среднее квадратическое отклонение; $N$ - объем выборки.

\section{Результаты исследования и их обсуждение}

Речная сеть рассматриваемой территории представлена рекой Обь (бассейн Карского моря) и ее притоками. Рассматриваемые реки: левобережные притоки р. Обь - Васюган с притоками (Чижапка, Нюрюлька и другие), Большой Юган, Чая с притоками (Икса, Андарма, Бакчар), Шегарка; правобережные притоки р. Обь - Тым, Вах, Тром-Юган, Лямин и другие. Границы водоразделов данных притоков Оби расположены в сильно заболоченной зоне, что в значительной степени определяет гидрохимический облик этих рек. Малые водотоки извилисты, с малыми уклонами (падение 5-10 см на 1 км) и со слабо выраженными водоразделами. Долины рек слабо разработанные, неясно выраженные, ассиметричные; преобладающая ширина 4-6 км. Реки, пересекающие болота, имеют низкие топкие берега и часто сливаются с займищами и сорами. Поймы рек двухсторонние, пересеченные старицами и ложбинами, с наличием дугообразных грив высотой 3-4 м, между которыми расположены болота. Степень заболоченности рек достигает 35-55 \%. Значительная часть поверхностных вод таежной зоны Западной Сибири сосредоточена в многочисленных водоемах, представленных в основном небольшими по объему и площади внутриболотными пойменными озерами. Их количество в целом возрастает от южной границы таежной зоны к северу по мере увеличения степени увлажнения территории.

Болота покрывают в основном водораздельные пространства и широкие террасы рек, образуя крупнейшие в мире болотные системы площадью до 50 тыс. км² (Васюганское болото и другие). Особенностью региона является распространение болот разного типа с преобладанием верховых (олиготрофных) грядово-мочажинных болот, достигших оптимального развития и занимающих почти сплошь водораздельные пространства и плоские террасы. Широко распространенные болотные микроландшафтыгрядово-мочажинный и грядово-мочажинныйозерковый комплексы, занимающие центральные и склоновые участки болотных массивов. Моховолесные, лесные и моховые микроландшафты расположены по склонам и окрайкам болот. Долины рек в пределах рассматриваемой зоны, в частности долины реки Васюган, также сильно заболочены, однако здесь широкое распространение имеют мезотрофные (переходные) и эвтрофные (низинные) болота.

По химическому составу воды верховых и переходных болот в среднем характеризуются как пресные с очень малой минерализацией (по сумме главных ионов $\Sigma$ ), гидрокарбонатные кальциевые, по рН кислые. Воды низинных болот также пресные, но уже со средней (в ряде случаев - с повышенной) минерализацией, по ионному составу - в целом гидрокарбонатные кальциевые, по $\mathrm{pH}$ - слабокислые и нейтральные. Для вод всех исследованных болот характерно высокое содержание органического вещества (OB; по величине ПО 68-90 мгО/дм $\left.{ }^{3}\right)$, аммонийного азота (2-4 мг/дм $\left.{ }^{3}\right)$, общего железа $(1,4-3,4$ мг/дм³ $)$. Широ- 
кое распространение болот разного типа определяет специфику химического состава речных и озерных вод исследуемого региона.

Озёрные воды исследуемого региона в среднем характеризуются как пресные с минерализацией от малой (чаще - для внутриболотных озёр) до средней, гидрокарбонатные кальциевые, по величине $\mathrm{pH}$ - от кислых до слабощелочных. Минерализация и рН внутриболотных озёр во многих случаях ниже соответствующих показателей воды рек, в водосборах которых они расположены, а минерализация пойменных озер в межень в ряде случаев, напротив, может быть несколько выше. Закономерно отмечается достаточно высокое содержание ОВ и продуктов их трансформации (табл. 1, 2).

Воды рек исследуемого региона, принимающих болотный сток с болот разного типа трофности, в среднем характеризуются как пресные с малой и средней минерализацией, гидрокарбонатные кальциевые (по классификации О.А. Алёкина [20]), по вели- чине $\mathrm{pH}$ - от слабокислых (преимущественно воды малых и средних рек в весенний период) до слабощелочных (чаще - в летний период во второй половине), содержат большое количество органических веществ - от 20 до 50 мгО/дм ${ }^{3}$ по величине ПО (табл. 1). Согласно карте гидрохимической зональности органического вещества, исследованные реки относятся к

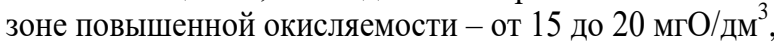
что определяется высокой степенью заболоченности их водосборов [21]. Модуль годового стока органического вещества, выносимого реками этого региона, варьирует на уровне 3-10 т/км², значительно превышая модуль среднемноголетнего стока ОВ рек России $[22,23]$. В составе ОВ идентифицирован широкий перечень различных соединений, включая углеводороды, фенолы, карбоновые кислоты, хлорсодержащие вещества и др. В значительных количествах обнаружены и продукты трансформации ОВ (например, $\mathrm{NH}_{4}{ }^{+}$и $\mathrm{NO}_{2}$ ), а также ряд металлов, особенно $\mathrm{Fe}$.

Таблица 1. Средние арифметические значения (А) гидрохимических показателей рек и озер на территории Томской области и погрешности их определения $\left(\delta_{A}\right)$

Table 1. Arithmetic means $(A)$ of hydrochemical characteristics of rivers and lakes on the area of Tomsk region and errors of determination $\left(\delta_{A}\right)$

\begin{tabular}{|c|c|c|c|c|c|c|c|c|c|c|c|}
\hline \multirow{2}{*}{ Водный объект/Water body } & \multirow{2}{*}{$\begin{array}{l}\text { Показатель } \\
\text { Indicator }\end{array}$} & \multirow{2}{*}{$\begin{array}{l}\mathrm{pH}, \text { ед. } \\
\mathrm{pH} \text { unit }\end{array}$} & $\Sigma$ & $\mathrm{Cl}^{-}$ & ПО/PO, & БО/BO & $\mathrm{NO}_{3}^{-}$ & $\mathrm{NO}_{2}^{-}$ & $\mathrm{NH}_{4}^{+}$ & $\mathrm{Fe}$ & $\mathrm{Cu}$ \\
\hline & & & \multicolumn{2}{|c|}{$\mathrm{M \Gamma} / \mathrm{дm}^{3} / \mathrm{mg} / \mathrm{dm}^{3}$} & \multicolumn{2}{|c|}{$\mathrm{мг \textrm {O }} / \mathrm{дm}^{3} / \mathrm{mgO} / \mathrm{dm}^{3}$} & \multicolumn{5}{|c|}{$\mathrm{Mг} / \mathrm{dm}^{3} / \mathrm{mg} / \mathrm{dm}^{3}$} \\
\hline \multirow{2}{*}{ p. Васюган/the Vasyugan river } & $A$ & 6,95 & 138,5 & 3,9 & 22,71 & 47,41 & 2,263 & 0,098 & 2,324 & 1,378 & 1,6 \\
\hline & $\delta_{\mathrm{A}}$ & 0,05 & 9,0 & 0,3 & 1,42 & 3,26 & 0,706 & 0,038 & 0,487 & 0,141 & 0,3 \\
\hline \multirow{2}{*}{$\begin{array}{l}\text { p. Чижапка (притокр. Васюган) } \\
\text { the Chizhapka river (tributary of the } \\
\text { Vasyugan river) }\end{array}$} & $A$ & 7,55 & 318,69 & 6,51 & 20,87 & 44,63 & 1,460 & 0,033 & 0,707 & 1,400 & 9,3 \\
\hline & $\delta_{A}$ & 0,11 & 51,63 & 1,73 & 4,00 & 4,11 & 0,401 & $0,009 \mid$ & 0,138 & 0,263 & 4,6 \\
\hline \multirow{2}{*}{$\begin{array}{l}\text { p. Нюролька (приток р. Васюган) } \\
\text { the Nyurolka river (tributary of the } \\
\text { Vasyugan river) }\end{array}$} & $A$ & 7,25 & 183,93 & 2,41 & 20,19 & - & 1,204 & 0,017 & 1,018 & 1,495 & 1,4 \\
\hline & $\delta_{A}$ & 0,13 & 37,14 & 1,16 & 3,16 & - & 0,091 & 0,014 & 0,118 & 0,293 & 0,4 \\
\hline \multirow{2}{*}{$\begin{array}{l}\text { Прочие притоки р. Васюган } \\
\text { other tributaries of the Vasyugan river }\end{array}$} & $A$ & 6,57 & 158,65 & 14,54 & 40,96 & 98,34 & 6,636 & 0,065 & 2,956 & 3,026 & 4,7 \\
\hline & $\delta_{A}$ & 0,10 & 11,13 & 3,32 & 5,69 & 7,64 & 1,401 & 0,007 & 0,248 & 0,165 & 1,1 \\
\hline \multirow{2}{*}{ р. Парабель/the Parabel river } & $A$ & 6,80 & 224,97 & 2,50 & 18,98 & 50,70 & 1,784 & 0,003 & 1,870 & 0,827 & 10,6 \\
\hline & $\delta_{A}$ & 0,15 & 24,93 & 0,25 & 2,68 & 10,25 & 1,183 & 0,001 & 0,490 & 0,187 & 8,1 \\
\hline \multirow{2}{*}{$\begin{array}{l}\text { p. Чузик (приток р. Парабель) } \\
\text { the Chuzik (tributary of the Parabel river) }\end{array}$} & $A$ & 7,57 & 284,31 & 3,05 & 21,39 & 34,65 & 0,153 & 0,027 & 0,518 & 0,680 & 0,2 \\
\hline & $\delta_{A}$ & 0,28 & 32,51 & 0,35 & 2,41 & 3,02 & 0,051 & \begin{tabular}{|l|}
0,019 \\
\end{tabular} & \begin{tabular}{|l|}
0,132 \\
\end{tabular} & \begin{tabular}{|l|}
0,082 \\
\end{tabular} & 0,2 \\
\hline \multirow{2}{*}{$\begin{array}{l}\text { Левые притоки р. Обь от устья р. Ва- } \\
\text { сюган до г. Стрежевой } \\
\text { Left tributaries of the Ob river from the } \\
\text { mouth of the Vasyugan river to the Stre- } \\
\text { zhevoy town }\end{array}$} & $A$ & 6,48 & 87,08 & 6,14 & 19,35 & 89,50 & 0,540 & 0,005 & 1,507 & 5,683 & 3,7 \\
\hline & $\delta_{\mathrm{A}}$ & 0,34 & 15,80 & 1,48 & 13,85 & 18,08 & 0,420 & 0,002 & 0,518 & 3,359 & 1,9 \\
\hline \multirow{2}{*}{$\begin{array}{l}\text { Правые притоки р. Обь от устья р. Ва- } \\
\text { сюган до г. Стрежевой } \\
\text { Right tributaries of the Ob river from the } \\
\text { mouth of the Vasyugan river to the Stre- } \\
\text { zhevoy town }\end{array}$} & $A$ & 6,32 & 122,43 & 12,71 & 35,80 & 57,91 & 2,757 & 0,365 & 1,725 & 2,374 & 2,7 \\
\hline & $\delta_{A}$ & 0,27 & 26,33 & 3,64 & 2,60 & 4,93 & 0,606 & 0,151 & 0,269 & 0,462 & 1,5 \\
\hline \multirow{2}{*}{ p. Чaя/the Chaya river } & $A$ & 7,64 & 403,99 & 9,19 & 20,27 & 53,80 & 2,997 & 0,078 & 1,287 & \begin{tabular}{|l|}
1,140 \\
\end{tabular} & 1,7 \\
\hline & $\delta_{A}$ & 0,12 & 27,8 & 0,8 & 2,33 & \begin{tabular}{l|l}
9,66 \\
\end{tabular} & 0,893 & 0,021 & 0,213 & \begin{tabular}{|l|}
0,137 \\
\end{tabular} & 0,4 \\
\hline \multirow{2}{*}{$\begin{array}{l}\text { p. Гавриловка (приток р. Икса) } \\
\text { the Gavrilovka river (tributary of the Iksa } \\
\text { river) }\end{array}$} & $A$ & 6,44 & 204,3 & 4,5 & 80,17 & 152,20 & 1,186 & 0,009 & 3,520 & 12,074 & 7,5 \\
\hline & $\delta_{A}$ & 0,08 & 60,2 & 1,3 & 9,56 & 29,18 & 0,300 & 0,005 & 0,869 & 5,739 & 5,5 \\
\hline \multirow{2}{*}{$\begin{array}{l}\text { Озера южно- и среднетаежной подзон в } \\
\text { Томской области } \\
\text { Lakes of South and Middle taiga subzones } \\
\text { in Tomsk region }\end{array}$} & $A$ & 5,04 & 54,4 & 4,9 & 15,47 & 40,94 & 0,840 & 0,007 & 0,881 & 1,146 & 3,8 \\
\hline & $\delta_{A}$ & 0,36 & 31,2 & 3,7 & 5,63 & 10,06 & 0,546 & 0,003 & 0,205 & 0,880 & 2,3 \\
\hline \multicolumn{12}{|c|}{ Антропогенные объекты/Anthropogenous objects } \\
\hline Шламовый амбар/Oil-waste pond & \begin{tabular}{l|}
$A$ \\
\end{tabular} & 7,99 & 7308,5 & 3874,4 & 62,70 & 207,77 & 4,958 & 0,026 & 1,595 & 19,277 & 7,2 \\
\hline
\end{tabular}


Таблица 2. Средние арифметические значения (А) гидрохимических показателей рек на территории ХантыМансийского автономного округа, болотных вод на территории Томской области и ХантыМансийского автономного округа и погрешности их определения $\left(\delta_{A}\right)$

Table 2. Arithmetic means (A) of hydrochemical characteristics of rivers on the area of the Khanty-Mansi Autonomous Okrug, mires water on the area of Tomsk region and the Khanty-Mansi Autonomous Okrug, errors of their determination $\left(\delta_{A}\right)$

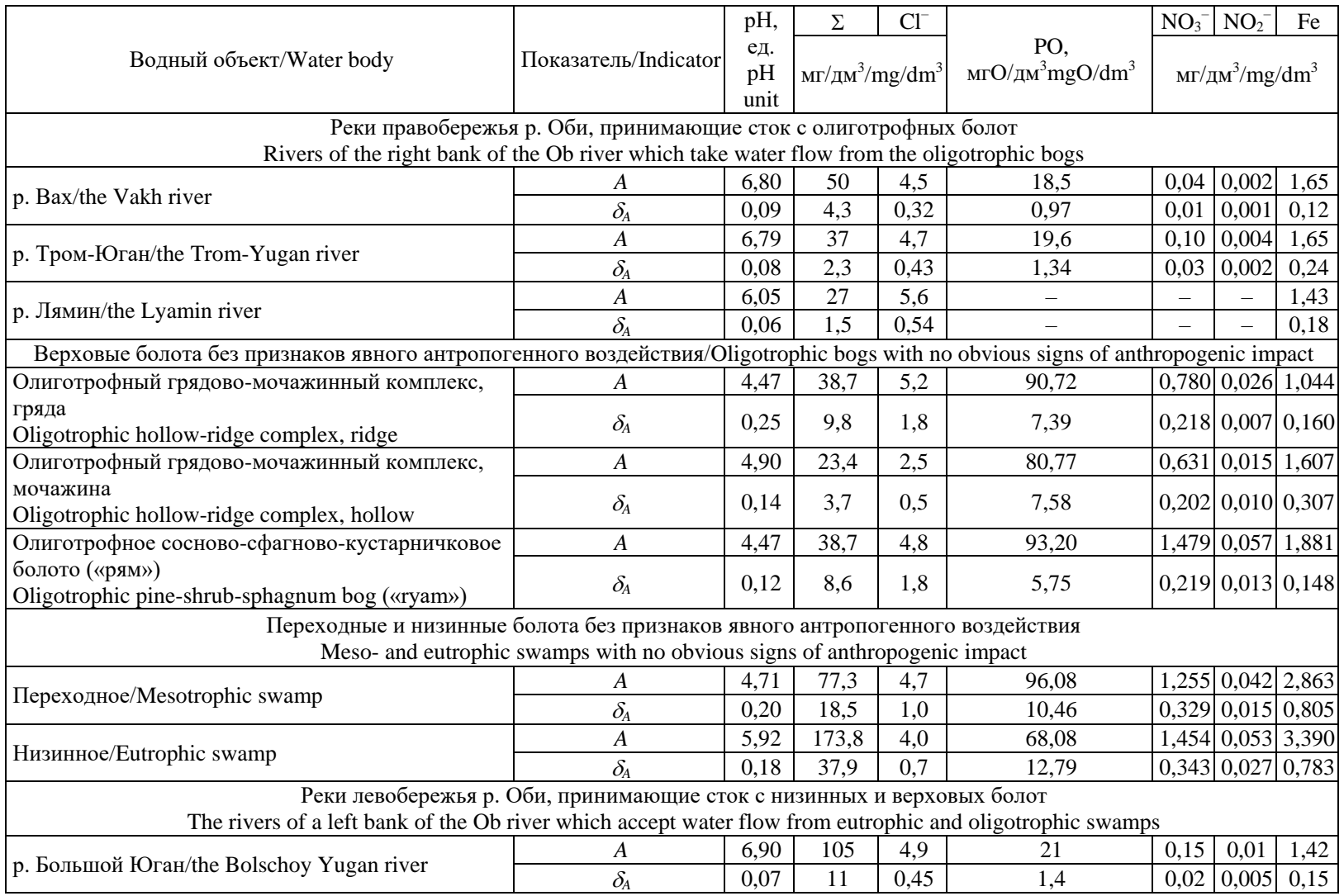

Содержание растворенного кислорода в зимнюю межень в водах многих малых рек (а в ряде случаев средних и больших) снижается вплоть до уровня, при котором начинаются заморные явления. Основной закономерностью пространственно-временных изменений является увеличение общей минерализации воды в зимнюю межень на фоне увеличения подземной составляющей водного стока. Влияние болот разного типа на химический состав исследованных рек выражено наиболее отчетливо по таким важным показателям, как $\mathrm{pH}$, общая минерализация и содержание органических веществ. Обобщение многолетних данных Росгидромета позволило выявить ряд отличительных особенностей рек, принимающих сток с верховых и низинных болот (табл.1, 2). Реки левобережья р. Оби (p. Васюган, p. Большой Юган) имеют более высокую минерализацию воды ( $\Sigma 100-160$ мг/дм $\left.{ }^{3}\right)$ и $\mathrm{pH}$ на уровне нейтральных вод (pH7,0-7,5) по сравнению с правобережными притоками реки Лямин, Вах, Тром Юган ( $\Sigma 27-50$ мг/дм $\left.{ }^{3}\right)$ при $\mathrm{pH}=6,6-6,9$. Пониженная минерализация рек правобережья р. Оби обусловлена в основном более высокой интенсивностью водообмена и худшей дренированностью левобережной части Обского бассейна, что обеспечивает более высокую минерализацию подземной составляющей речного стока. Влияние притока болотных вод на состояние рек и озер в наибольшей степени сказывается на со- держании $\mathrm{OB}$, их соединений с некоторыми металлами и продуктов трансформации. Различия по геохимическим показателям болотных вод выявляются не только для верховых, переходных и низинных болот, но и для болот с разным соотношением лесных и топяных фитоценозов и геоморфологического положения, что, по сути, отражает общую зависимость химического состава болотных вод от времени и площади контакта вод с минеральными частицами.

Сопоставление среднемноголетних содержаний ряда химических веществ в реках и болотах исследуемого региона с действующими нормативами предельно допустимых концентраций для вод рыбохозяйственного и хозяйственно питьевого водопользования свидетельствует о том, что не только в болотных, но и в речных водах эти показатели в большинстве случаев превышают ПДК (рисунок). Высокие фоновые содержания ряда химических веществ (OВ по ХПК и ПО, аммонийного азота, общего железа, марганца, меди) в реках таежной зоны Западной Сибири, определяющихся влиянием болотного стока, ставят под вопрос применение общепринятых методов нормирования антропогенной нагрузки на основе требуемых стандартов предельно допустимых концентраций приоритетных загрязняющих веществ. В настоящее время для установления допустимой нагрузки на водотоки используется гидролого- 
гидрохимический подход, основанный на теоретической зависимости концентрации загрязняющих веществ в контрольном створе ниже по течению от выпуска сбрасываемых в водоток сточных вод [23]:

$$
C_{\mathrm{p}}=C_{\phi}+\frac{C_{\mathrm{cT}}-C_{\phi}}{n}
$$

где $C_{\text {ст }}-$ концентрация исследуемого вещества в сточных водах; $C_{\phi}$ - концентрация вещества в фоновом створе (выше по течению от выпуска сточных вод); $n$ - кратность разбавления сточных вод.

Контроль качества воды требует выполнения условия: $C \leq$ ПДК хозяйственно- питьевого или рыбохозяйственного водопользования. Вместе с тем для отдельных регионов условия формирования природного гидрохимического режима таковы, что по ряду ингредиентов их содержание превышает нормативы ПДК. Так, в работе [24] в воде р. Кама содержание железа и марганца превышает рыбохозяйственные ПДК, что определяется особенностями почвенногеохимического строения водосборной территории. Необходимость включения в общую схему нормирования антропогенной нагрузки экологических критериев, учитывающих региональную специфику химического состава вод, отмечается и другими авторами [25-27].

В соответствии с данными [3, 6-9, 11-13], речные и озерные воды таежной зоны Западной Сибири также не соответствуют принятым в России нормативам рыбохозяйственного и хозяйственно-питьевого водопользования по величине $\mathrm{pH}$, перманганатной и бихроматной окисляемости, содержанию веществ, идентифицируемых как «нефтепродукты», фенолам, азоту аммонийному и нитритному, фосфатам, $\mathrm{Si}, \mathrm{Fe}$, $\mathrm{Al}, \mathrm{Mn}, \mathrm{Cu}, \mathrm{Zn}$ (рисунок).

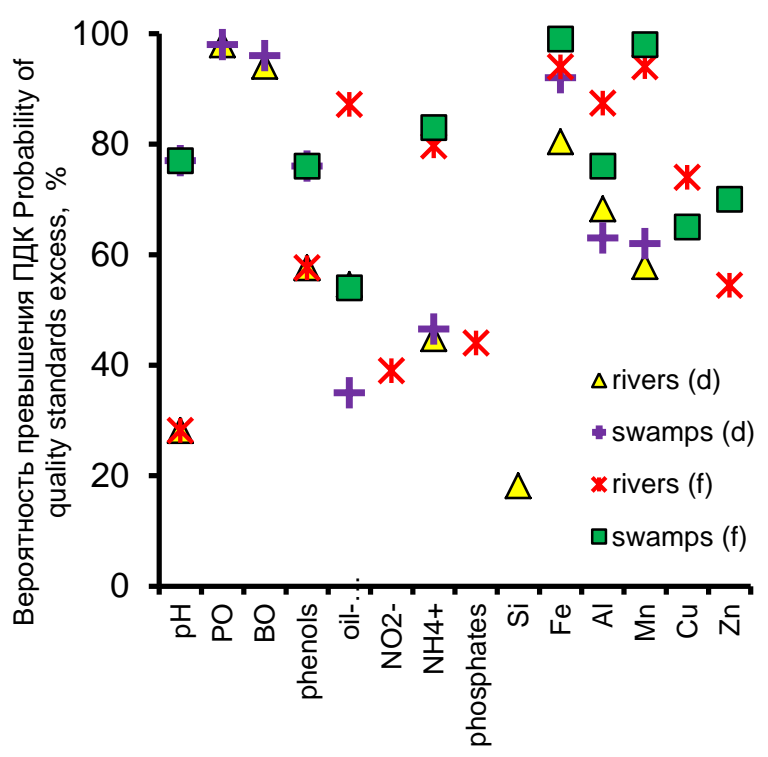

Рисунок. Вероятность превышения хозяйственноnитьевых (d) и рыбохозяйственных (f) нормативов качества в поверхностных водах таежной зоны Западной Сибири

Figure. Probability of drinking (d) and fishery (f) quality standards excess for surface waters of taiga zone of Western Siberia
Как видно из рисунка, степень превышения нормативов качества болотных и гидравлически связанных с ними речных и озерных вод в целом такова, что их использование в хозяйственно-питьевых ирыбохозяйственных целях становится невозможным. Соответственно, уже фоновое эколого-геохимическое состояние водных объектов заболоченных территорий таежной зоны Западной Сибири без признаков явного антропогенного воздействия (сброс сточных вод, осушение, строительство дорог, производственных объектов, мест размещения отходов) в основном соответствует категории «загрязненных» и «грязных» вод согласно [27].

В связи с этим оценка степени антропогенной нагрузки на водные объекты с такими высокими фоновыми содержаниями органического вещества, биогенных элементов, тяжелых металлов требует поиска наиболее индикативных показателей, имеющих низкие фоновые содержания, превышение которых позволяет оперативно выявлять уровень антропогенной нагрузки на исследованные водные объекты. Согласно анализу данных табл. 1, 2, к таким показателям, бесспорно, относятся ионы хлора (хлориды), фоновая концентрация которых в исследованных речных и озерных водах колеблется на уровне 4-16 мг/дм³, тогда как на антропогенных объектах (шламовых амбарах) она достигает 3800 мг/дм ${ }^{3}$. Кроме того, согласно данным [28], низкое содержание хлоридов вообще характерно для поверхностных вод таежной зоны Западной Сибири, так как его природное поступление в поверхностные воды обычно не превышает $15 \mathrm{мг} /$ дм $^{3}$. Именно поэтому наиболее характерными показателями загрязнения являются не повышенные концентрации нефтепродуктов, фенолов, $\mathrm{NO}_{2} \mathrm{NH}_{4}^{+}, \mathrm{Fe}, \mathrm{Cu}$ (в значительной степени - следствие болотных процессов), а хлоридные ионы. При этом антропогенное поступление хлоридов может быть связано либо с их использованием в процессах водоподготовки и водоотведения (дезинфекцией сточных вод), либо с поступлением в окружающую среду минерализованных подземных вод, используемых в системах поддержания пластового давления при добыче углеводородного сырья (табл. 1). Соответственно, при организации мониторинга в ряде случаев достаточно ограничиться несколькими характерными гидрохимическими показателями, среди которых обязательно должны присутствовать хлоридные ионы.

Необходимо также отметить, что ограничения по некоторым видам деятельности не всегда эффективны. Например, требование по обеспечению ПДК в болотных водах можно выполнить только при ликвидации болота как водного объекта, поскольку по определению болото характеризуется наличием торфа и, следовательно, высоким содержанием ОВ и продуктов его трансформации в болотных водах, а затем и в водах других водных объектов. С большой вероятностью подобное противоречие сохранится и при внедрении в практику подходов на основе использования наилучших доступных технологий. С учетом этого, возможно, целесообразно применение подхода на 
основе соблюдения региональных фоновых концентраций, а также учета степени разбавления сточных вод в различные фазы водности - в периоды половодья и межени.

\section{Заключение}

Химический состав поверхностных вод в таежной зоне Западной Сибири в значительной степени определяется природными процессами заболачивания, вследствие чего наблюдается нарушение рыбохозяйственных и хозяйственно-питьевых нормативов качества по величине $\mathrm{pH}$, содержанию $\mathrm{NH}_{4}^{+}, \mathrm{Fe}, \mathrm{Al}, \mathrm{Mn}$, фенолов, веществ, идентифицируемых как «нефтепродукты», а также рыбохозяйственных - по содержанию $\mathrm{NO}_{2}^{-}$, фосфатов, $\mathrm{Cu}, \mathrm{Zn}$ и хозяйственнопитьевых нормативов - по величине бихроматной и перманганатной окисляемости. Антропогенное влияние достаточно надежно выявляется по повышению содержаний хлорид-иона (в пределах ПДК, но в 2-3 раза выше фоновых значений).

Болота и заболоченные территории, широко распространенные в этом регионе, вовлечены в хозяйственную деятельность и имеют важное значение как источники многих ресурсов (торф, дикорастущие растения и др.), играют особую роль в поддержании биологического разнообразия. Однако в настоящее время использование болот в Западной Сибири недо-

\section{СПИСОК ЛИТЕРАТУРЫ}

1. Охрана окружающей среды в территориальном ЗападноСибирском комплексе / В.А. Шишов, В.Ю. Шеметов, В.И. Рябченко, В.П. Парфенов. - М.: Всесоюзный научноисследовательский институт организации, управления и экономики нефтегазовой промышленности ВНИИОЭНГ, 1988. $53 \mathrm{c}$.

2. Солнцева Н.П. Добыча нефти и геохимия природных ландшафтов. - М.: МГУ, 1998. - 376 с.

3. Адам А.М. Оценка экологического состояния территории Западной Сибири в целях обеспечения экологической безопасности в контексте устойчивого природопользования // Охрана природы: сборник статей / под ред. А.Е. Березина. Томск: Изд-во НТЛ, 2005. - С. 1-12.

4. Ecosystem recovery and natural degradation of spilled crude oil in peat bog ecosystems of West Siberia / W. Bleuten, E. Lapshina, W. Ivens, V. Shinkarenko, E. Wiersma // International Peat Journal. - 1999. - № 9. - Р. 73-82.

5. Пологова Н.Н., Лапшина Е.Д. Накопление углерода в торфяных залежах Большого Васюганского болота // Большое Васюганское болото. Современное состояние и процессы развития / под ред. М.В. Кабанова. - Томск: Изд-во ИОА СО РАН, 2002. - C. 174-186

6. Spatial patterns of the evolution of the chemical composition and discharge of river water in the $\mathrm{Ob}$ river basin / O.G. Savichev, A.K. Mazurov, I.I. Pipko, V.I. Sergienko, I.P. Semiletov // Doklady Earth Sciences. - 2016. - V. 466. - P. 1. - P. 47-51. DOI: 10.1134/S1028334X16010141.

7. Dynamics of dissolved inorganic carbon and $\mathrm{CO} 2$ fluxes between the water and the atmosphere in the main channel of the $\mathrm{Ob}$ river I.I. Pipko, S.P. Pugach, O.G. Savichev, I.A. Repina, N.E. Shakhova, Y.A. Moiseeva, K.V. Barskov, V.I. Sergienko, I.P. Semiletov // Doklady Chemistry. - 2019. - V. 484. - P. 2. P. 52-57. DOI: 10/1134/S0012500819020101.

8. Vegetation characteristics and eco-hydrological processes in a pristine mire in the Ob River valley (Western Siberia) / A.M. Schipper, R. Zeefat, F. Tanneberger, J.P. van Zuidam, W. Hahne, S. Schep, S. Loos, W. Bleuten, H. Joosten, E.D. Lapshina, M.J. Wassen // Plant Ecol. - 2007. - V. 193. P. 131-145. DOI 10.1007/s11258-006-9253-x. статочно регламентировано и научно обосновано [2426]. Несмотря на правовой статус болот, определенный Водным кодексом Российской Федерации, до сих пор не разработана нормативная и методическая основа для придания законной силы использованию болот. Учитывая масштабность вовлечения их в хозяйственную деятельность, назрела острая необходимость научно-обоснованных предложений по разработке нормативов допустимого воздействия на болота и реки-водоприемники болотного стока. Одним из аспектов такой работы является выявление закономерностей формирования гидрохимического режима болот и рек с высокой степенью заболоченности водосборов в естественных условиях.

Определение региональных значений фоновых концентраций и допустимых значений кратности разбавления (для водохозяйственных участков) целесообразно поручить подразделениям Росгидромета, которые в настоящее время одновременно являются и основным источником информации, и согласующим органом при разработке и утверждении нормативов допустимых сбросов. Технически такие данные могут представлять региональные карты изолиний (для средних рек), однородных районов (для малых рек, болот и озер) или участков больших рек, действующие в течение нескольких лет.

9. Гидрология заболоченных территорий зоны многолетней мерзлоты Западной Сибири/ под ред. С.М. Новикова. - СПб.: BBM, 2009. - $536 \mathrm{c}$.

10. Транспорт загрязняющих веществ по крупным рекам европейского Севера и Сибири / А.М. Никаноров, В.А. Брызгало, О.С. Решетняк, М.Ю. Кондакова // Водные ресурсы. - 2015. T. 42. - № 3. - C. 279-287. DOI: 10.7868/S0321059615010101.

11. Shotyk W. Peat bog archives of atmospheric metal deposition: geochemical evaluation of peat profiles, natural variations in metal concentrations, and metal enrichment factors // Environmental Reviews. - 1996. - V. 4. - P. 149-183.

12. Pokrovsky O.S., Karlsson J., Giesle R. Freeze-thaw cycles of Arctic thaw ponds remove colloidal metals and generate low-molecularweight organic matter // Biogeochemistry. - 2018. - V. 137. P. 321-336. DOI: https://doi.org/10.1007/s10533-018-0421-6.

13. Biogechimistry of dissolved carbon, major, and trace elementary during spring flood periods on the Ob River / O.S. Pokrovsky, L.G. Kolesnichenko, R.M. Manasypov, L.S. Shirokova, J. Karlsson, S.N. Kirpotin // Hydrological Processes. - 2019. - P. 1-16. DOI: 10.1002.hyp. 13424.

14. Zemtsov V.A., Savichev O.G. Resources, regime and quality of surface waters in the $\mathrm{Ob}$ river basin: history, current state and problems of research // International Journal of Environmental Studies. - 2015. - V. 72. - № 3. - P. 386-396. URL: http://dx.doi.org/10.1080/00207233.2015.1019299 (дата обращения 05.07.2019).

15. Benedini M., Tsakiris G. Water quality modelling for rivers and streams. - Dordrecht: Springer, 2013. - 288 p.

16. Фоновые показатели эколого-геохимического состояния вод верховых болот в таежной зоне на территории Российской Федерации / Т.М. Потапова, М.Л. Марков, А.П. Носаль, О.Г. Савичев // Известия Томского политехнического университета. Инжиниринг георесурсов. - 2018. - Т. 329. - № 9. C. $83-92$.

17. Shvartsev S.L. Geochemistry of fresh groundwater in the main landscape zones of the Earth // Geochemistry International. 2008. - V. 46. - № 13. - P. 1285-1398.

18. Р 52.24.309-2004. Рекомендации. Организация и проведение режимных наблюдений за загрязнением поверхностных вод суши на сети Росгидромета. Дата введения 2006-01-01. Феде- 
ральная служба по гидрометеорологии и мониторингу окружающей среды. - М.: Метеоагентство Росгидромета, 2005. $85 \mathrm{c}$.

19. РД 52.24.622-2017. Порядок проведения расчета условных фоновых концентраций химических веществ в воде водных объектов для установления нормативов сбросов сточных вод Дата введения 14.06.2017 г. - М.; Ростов-на-Дону: Росгидромет, ГХИ, 2017. - 96 с.

20. Алекин О.А. Основы гидрохимии. - Л.: Гидрометеоиздат, 1970. $-444 \mathrm{c}$.

21. Смирнов М.П., Тарасов М.Н. Гидрохимическая карта окисляемости речных вод Европейской части СССР // Гидрохимические материалы. - 1970. - Т. 54. - С. 3-32.

22. Никаноров А.М. Региональная гидрохимия. - Ростов на Дону: Изд-во НОК, 2011. - 389 с

23. Никаноров А.М. Гидрохимия. - Л.: Гидрометеоиздат, 2001. $444 \mathrm{c}$.
24. Лепихин А.П., Мирошниченко С.А., Садохина Е.Л. Проблемы регламентации техногенных воздействий на водные объекты // Эколого-водохозяйственный вестник. - 1998. - Вып. 3. C. 27-29.

25. Черногаева Г.М., Кузьмич В.Н., Бердников С.В. Проблемы нормирования стока химических веществ с водосборной территории // Метеорология и гидрология. - 2003. - № 3. - С. 75-82.

26. Нормирование вредных воздействий на водные объекты в бассейне малой реки / А.Е. Косолапов, О.А. Клименко, Е.В. Полуэктов, В.Г. Дубинина // Водное хозяйство России. 2001. - T. 3. - № 2. - C. 135-158.

27. ГОСТ 17.1.2.04-77. Показатели состояния и правила таксации рыбохозяйственных водных объектов. - М.: Государственный комитет СССР по стандартам, 1977. - 17 с.

28. Посохов Е.В. Формирование хлоридных вод гидросферы. - Л.: Гидрометеоиздат, 1977. - 247 с.

Поступила 14.07.2019 2.

\section{Информация об авторах}

Марков М.Л., кандидат географических наук, руководитель отдела экспериментальных гидрологических исследований и математического моделирования, Государственный гидрологический институт.

Потапова T.M., кандидат химических наук, доцент Института наук о Земле, Санкт-Петербургский государственный университет.

Задонская O.B., старший научный сотрудник лаборатории озер и водохранилищ, Государственный гидрологический институт. 
UDC 550.46

\title{
REGIONAL FEATURES OF ECOLOGICAL GEOCHEMICAL CONDITION OF SURFACE WATER BODIES IN TAIGA ZONE OF WESTERN SIBERIA
}

\author{
Mikhail L. Markov'1, \\ 2019mml@mail.com \\ Tatyana M. Potapova², \\ ptm2000@mail.ru \\ Olga V. Zadonskaya ${ }^{1}$, \\ ov-zadon@yandex.ru \\ 1 State Hydrological Institute, \\ 23, 2nd line of Vasilyevsky island, Saint Petersburg, 199053, Russia. \\ 1 St.-Petersburg State University, \\ 7/9, Universitetskaya embankment, Saint Petersburg, 199034, Russia.
}

\begin{abstract}
Relevance. Quantitative assessment of ecological and geochemical state of surface waters and their formation factors is one of the most important stages of water resources management which determines the effectiveness of measures for integrated use and protection of waters.

The aim of the research is the quantitative assessment of regional features of the current ecological and geochemical state of surface water bodies in the taiga zone of Western Siberia.

Methods: methods of water chemical composition researches (titrimetric, turbidimetric, photometric, ion chromatography, inversionvoltamperometric, atomic absorption, mass spectrometric with inductively coupled plasma); statistical methods.

Results and conclusions. The authors have considered regional features of ecological and geochemical state of surface water bodies in taiga zone of Western Siberia by the results of analysis of the materials of long-term hydrochemical observations of Roshydromet and other organizations. It is shown that chemical composition of surface waters in the region is largely determined by the natural wetland processes, resulting in an excess of fishery and drinking quality standards for the $\mathrm{pH}$ value, the content of $\mathrm{NH}_{4}^{+}, \mathrm{Fe}, \mathrm{Al}, \mathrm{Mn}$, phenols, substances identified as "petroleum products», as well as fishery standards - for the content of $\mathrm{NO}_{2}{ }^{-}$, phosphates, $\mathrm{Cu}, \mathrm{Zn}$ and drinking - the value of bichromate and permanganate oxidability. It is established that anthropogenic influence is reliably detected by increasing the chloride ion content (within the maximum permissible concentrations, but 2-3 times higher than the background values). The authors developed the recommendations on hydrochemical monitoring. On the basis of regional background concentrations of pollutants and water discharge on the regime stations of Siberian rivers the degree of dilution of wastewater dropped into the rivers of strongly swampy watersheds can be determined. These calculations should be the basis for the approved standards of permissible impacts on the rivers of the taiga zone of Western Siberia.
\end{abstract}

\section{Key words:}

River waters, lake waters, swamp waters, chemical composition, taiga zone, Western Siberia.

\section{REFERENCES}

1. Shishov V.A., Shemetov V.Yu., Ryabchenko V.I., Parfenov V.P. Okhrana okruzhayushchey sredy $v$ territorialnom ZapadnoSibirskom komplekse [Environmental protection in the territorial West Siberian complex]. Moscow, VNIIOENG Publ., 1988. 53 p.

2. Solntseva N.P. Dobycha nefti i geokhimiya prirodnykh landshaftov [Oil production and geochemistry of natural landscapes]. Moscow, Moscow State University Press, 1998. 376 p.

3. Adam A.M. Otsenka ekologicheskogo sostoyaniya territorii Zapadnoy Sibiri v tselyakh obespecheniya ekologicheskoy bezopasnosti v kontekste ustoychivogo prirodopolzovaniya [Assessment of ecological state of the territory of Western Siberia in order to ensure environmental safety in the context of sustainable environmental management]. Okhrana prirody [Environmental protection] Ed. by A.E. Berezin. Tomsk, NTL Press, 2005. pp. 1-12.

4. Bleuten W., Lapshina E., Ivens W., Shinkarenko V., Wiersma E. Nakoplenie ugleroda $\mathrm{v}$ torfyanykh zalezhakh BolshogoVasuganskogo bolota [Carbon accumulation in peat bog deposits of the Great Vasyugan]. Bolshoe Vasuganskoe boloto. Sovremennoe sostoyanie i protsessy razvitiya [Big Vasyugan bog. Current status and development]. Tomsk, Institute of Atmospheric Optics SB RAS Publ., 2002. pp. 174-179.

5. Pologova N.N., Lapshina E.D. Nakoplenie ugleroda $v$ torfyanykh zalezhakh Bolshogo Vasyuganskogo bolota [Carbon accumulation in peat layers of Great Vasyugan bog]. Bolshoe Vasyuganskoe boloto. Sovremennoe sostoyanie $i$ protsessy razvitiya [Great
Vasyugan bog. Current sate and development]. Ed. by M.V. Kabanov. Tomsk, IOA SB RAS Publ., 2002. pp. 174-186.

6. Savichev O.G., Mazurov A.K., Pipko I.I., Sergienko V.I., Semiletov I.P. Spatial patterns of the evolution of the chemical composition and discharge of river water in the Ob river basin. Doklady Earth Sciences, 2016, vol. 466, P. 1, pp. 47-51. DOI: 10.1134/S1028334X16010141.

7. Pipko I.I., Pugach S.P., Savichev O.G., Repina I.A., Shakhova N.E., Moiseeva Y.A., Barskov K.V., Sergienko V.I., Semiletov I.P. Dynamics of dissolved inorganic carbon and $\mathrm{CO}_{2}$ fluxes between the water and the atmosphere in the main channel of the Ob river. Doklady Chemistry, 2019, vol. 484, P. 2, pp. 52-57. DOI: 10/1134/S0012500819020101.

8. Schipper A.M., Zeefat R., Tanneberger F., Van Zuidam J.P., Hahne W., Schep S., Loos S., Bleuten W., Joosten H., Lapshina E.D., Wassen M.J. Vegetation characteristics and eco-hydrological processes in a pristine mire in the Ob River valley (Western Siberia). Plant Ecol., 2007, vol. 193, pp. 131-145. DOI 10.1007/s11258006-9253-x.

9. Gidrologiya zabolochennykh territoriy zony mnogoletney merzloty Zapadnoy Sibiri [Hydrology of wetlands in the permafrost zone of Western Siberia]. Ed. by S.M. Novikov. St Petersburg, VVM Publ., 2009. $536 \mathrm{p}$

10. Nikanorov A.M., Bryzgalo V.A., Reshetnyak O.S., Kondakova M.Yu. Transport of pollutants along the major rivers of the European North and Siberia]. Water resources, 2015, vol. 42, no. 3, pp. 279-287. DOI: 10.7868/S0321059615010101. In Rus. 
11. Shotyk W. Peat bog archives of atmospheric metal deposition: geochemical evaluation of peat profiles, natural variations in metal concentrations, and metal enrichment factors. Environmental Reviews, 1996, vol. 4, pp. 149-183.

12. Pokrovsky O.S., Karlsson J., Giesle R. Freeze-thaw cycles of Arctic thaw ponds remove colloidal metals and generate lowmolecular-weight organic matter. Biogeochemistry, 2018, vol. 137, pp. 321-336. DOI: https://doi.org/10.1007/s10533-018-0421-6.

13. Pokrovsky O.S., Kolesnichenko L.G., Manasypov R.M., Shirokova L.S., Karlsson J., Kirpotin S.N. Biogechimistry of dissolved carbon, major, and trace elementary during spring flood periods on the Ob River. Hydrological Processes, 2019, pp. 1-16. DOI: 10.1002.hyp. 13424 .

14. Zemtsov V.A., Savichev O.G. Resources, regime and quality of surface waters in the $\mathrm{Ob}$ river basin: history, current state and problems of research. International Journal of Environmental Studies, 2015, vol. 72, no. 3, pp. 386-396. Available at: http://dx.doi.org/10.1080/00207233.2015.1019299 (accessed 05 July 2019).

15. Benedini M., Tsakiris G. Water quality modelling for rivers and streams. Dordrecht, Springer, 2013. 288 p.

16. Potapova T.M., Markov M.L., Nosal A.P., Savichev O.G. Background parameters of the ecological and geochemical condition of waters of oligotrophic bogs in the taiga zone in the Russian federation. Bulletin of the Tomsk Polytechnic University. Geo Assets Engineering, 2018, vol. 329, no. 9, pp. 83-92. In Rus.

17. Shvartsev S.L. Geochemistry of fresh groundwater in the main landscape zones of the Earth. Geochemistry International, 2008, vol. 46, no. 13, pp. 1285-1398.

18. Rekomendatsii $i$ organizatsiyai provedeniye rezhimnykh nablyudeniy za zagryazneniyem poverkhnostnykh vod sushi na seti Rosgidrometa [Recommendations. Organizing and conducting routine monitoring of surface water pollution on the Roshydromet network]. Moscow, Meteo agentstvo Rosgidrometa Publ., 2005. 85 p.

19. RD52.24.622-2017 Poryadok provedeniya raschetau fonovykh kontsentratsiy khimicheskikh veshchestv v vodnykh objektach [Procedure for calculating the background concentrations of chemicals in the water of water bodies in order to establish standards for wastewater discharges]. Moscow, Rostov-na-Donu, Rosgidromet, FGBU «SCHI», 2017.96 p.

20. Alekin O.A. Osnovy gidrokhimii [Bases of hydrochemistry]. Leningrad, Gidrometeoizdat Publ., 1970. 444 p.

21. Smirnov M.P., Tarasov M.N. Gidrokhimicheskaya karta okisleniya rechnykh vod Evropeyskoy chasti SSSR [Hydrochemical map of oxidation of river waters of the European part of the USSR]. Gidrokhimicheskie materialy, 1970, vol. 54, pp. 3-32.

22. Nikanorov A.M. Regionalnaya gidrokhimiya [Regional hydrochemistry]. Rostov on Don, NOK Press, 2011.389 p.

23. Nikanorov A.M. Gidrokhimiya [Hydrochemistry]. Leningrad, Gidrometeoizdat Publ., 2001. 444 p.

24. Lepikhin A.P., Miroshnichenko S.A., Sadokhina E.L. Problemy reglamentatsii tekhnogennykh vozdeystviy na vodnyye obekty [Problems of regulation of technogenic impacts on water bodies]. Ekologo-vodokhozyaystvenny vestnik, 1998, vol. 3, pp. 27-29.

25. Chernogaeva G.M., Kuzmich V.N., Berdnikov S.V. Problemy normirovaniya stoka khimicheskikh veshchestv s vodosbornoy territorii [Problems of rationing chemicals from the catchment area]. Meteorology and Hydrology, 2003, no. 3, pp. 75-82. In Rus.

26. Kosolapov A.E., Klimenko O.A., Poluektov E.V., Dubinina V.G. Normirovanie vrednykh vozdeystviy na vodnyye obyekty v basseyne maloy reki [Rationing of harmful effects on water bodies in the basin of a small river]. Vodnoyekhozyaystvo Rossii, 2001, vol. 3, no. 2, pp. 135-158.

27. GOST 17.1.2.04-77 Pokazateli sostoyaniya i pravila taksatsii vodnykh obyektov [SS 17.1.2.04-77 Status indicators and taxation rules for fishery water bodies]. Moscow, Goskomstandart, 1977. $17 \mathrm{p}$.

28. Posokhov E.V. Formirovanie khloridnykh vod gidrosfery [Formation of chloride waters of the hydrosphere]. Leningrad, Gidrometeoizdat Publ., 1977. 247 p.

Received: 14 July 2019.

\section{Information about the authors}

Mikhail L. Markov, Cand. Sc., head of the department of experimental hydrological researches and mathematical modelling, State Hydrological Institute.

Tatyana M. Potapova, Cand. Sc., senior lecturer, St.-Petersburg State University.

Olga V. Zadonskaya, senior researcher, State Hydrological Institute. 